\title{
Voces del pasado que retumban en el presente
}

$\mathrm{Z}^{17 \text { de agosto de 1950, Laureano Eleuterio Gómez Castro pro- }}$ Cnunció un largo discurso de posesión como el presidente 43 de la república de Colombia, ante los magistrados de la Corte Suprema de Justicia. Tras manejar los hilos del concierto político nacional por más de tres décadas como el líder más influyente del Partido Conservador, su ascenso a la primera magistratura del país — garantizada por la renuncia del candidato liberal Darío Echandía, ante la falta de garantías en la seguridad para el partido y para su persona - representaba una oportunidad excepcional para impulsar reformas profundas y sustanciales, plasmadas en el proyecto de reforma constitucional de 1951, con el fin de enderezar el rumbo civilizatorio que la nación perdió, según Gómez Castro, cuando los Gobiernos liberales de Enrique Olaya Herrera y Alfonso López Pumarejo, especialmente, promovieron una serie de cambios estructurales en materia social y económica. El discurso de posesión sintetiza, entonces, las posturas de un hombre que luchó sin tregua por la defensa de las leyes divinas y de la naturaleza, ambas enmarcadas en los "eternos principios de la ley moral, consubstancial con la naturaleza humana" (Gómez, 2013, p. 11). Por lo mismo, el discurso registra una estructura que definió la postura del nuevo presidente en torno a temas esenciales de su ideario político:

- La gloria jurídica de la república, imbricada con el "concepto cristiano de la vida del hombre y la sociedad civil”.

- La eficacia de la ley para tener "fundamentos sólidos no susceptibles de esfumarse entre la balumba de preceptos e interpretaciones". 
- La justificación de su papel histórico como un mandatario que tiene la tarea de "remediar" las fallas de la república, expresadas en el atraso civil y económico, así como en la politiquería como enfermedad de la esfera pública.

- La defensa de la "verdad" como elemento sustancial para garantizar la libertad.

- La dignidad de la persona humana para el ejercicio de una ciudadanía en la que debe primar la virtud de los hombres de bien.

- El restablecimiento del respeto inviolable de la vida humana frente a la violencia homicida, entendiendo que no se pueden sustituir las obligaciones morales ni olvidarse de "la justicia y la buena fe prescritas en las leyes eternas”.

- La pulcritud administrativa para contener el corruptor régimen de las comisiones ocultas.

- El trascendental papel de la Iglesia para limpiar de la mente popular "las punzadoras malezas del materialismo histórico que degradan la persona humana”, así como en el pasado ayudaron a "erradicar el salvajismo entre los pueblos aborígenes" y lideraron el proceso educativo de la república a través de colegios y universidades.

- Como parte esencial de ese proyecto de "limpieza y eficacia", el papel de la mujer como sostén de la institución familiar, sin que ello implique un ejercicio de ciudadanía porque "la mujer es la voz de la conciencia masculina”.

- La escuela y la universidad donde los jóvenes - varones, claro está- encontrarán los lugares idóneos para formar "hombres y ciudadanos, y no visionarios y sofistas”.

Los textos de Laureano Gómez Castro podrían considerarse como un acervo histórico valioso para acceder al pasado reciente del país, pero a pesar de que la mayoría de sus discursos fueron escritos, pronunciados o publicados hace más de sesenta años, sus palabras y sus 
posturas doctrinarias aún tienen vigencia en las discusiones políticas contemporáneas por cuanto resuenan y trascienden en la voz de los líderes y dirigentes que ostentan el poder. En consecuencia, el objetivo del capítulo está en analizar los ecos que el ideario laureanista tiene en los postulados de uno de los dirigentes más influyentes y representativos de la política nacional en el despuntar del siglo xxi: Álvaro Uribe Vélez ${ }^{1}$. El análisis tendrá como base conceptual y metodológica las categorías desarrolladas por el semiólogo argentino Eliseo Verón respecto al discurso político.

\section{Caracterización del discurso político}

En mayo de 2016, pocos meses antes de que el gobierno de Juan Manuel Santos y las Farc-eP sellaran el acuerdo de paz ${ }^{2}$, el expresidente y senador Álvaro Uribe Vélez ofreció una entrevista radial al programa que dirige el periodista Julio Sánchez Cristo. El tema e interés de los periodistas de la mesa de trabajo estaba en ahondar con el líder

1 Político colombiano que ocupó la presidencia durante dos periodos, 2002 a 2006 y 2006 a 2010. Senador de la república entre 1986 y 1994, cuando impulsó la reforma a la seguridad social a través de la Ley 100 de 1993. Como gobernador del departamento de Antioquia (1994 a 1998) comenzó a perfilar la denominada "política de seguridad democrática", apelando a controvertidas iniciativas como las cooperativas de seguridad privada (Convivir), muchas de ellas convertidas posteriormente en grupos paramilitares. Regresó a la dinámica parlamentaria en 2014 en calidad de senador, asumiendo la vocería de la oposición al proceso de negociación entre las Farc-EP y el gobierno de Juan Manuel Santos.

2 El proceso de negociación entre el gobierno de Juan Manuel Santos y la insurgencia de las Farc-EP se remonta a 2011, cuando delegados de ambas partes iniciaron conversaciones secretas en La Habana, Cuba. En Colombia la noticia se filtró el 12 de agosto de 2012 y fue confirmada por el presidente Santos el 4 de septiembre de ese mismo año, mediante una alocución. La negociación se centró en seis puntos: 1) desarrollo agrario integral; 2) participación política; 3) fin del conflicto; 4) solución al problema de las drogas ilícitas; 5) reparación a las víctimas, y 6) mecanismos de refrendación de lo acordado. Desde que se conoció la noticia, Álvaro Uribe Vélez se convirtió en uno de los más enconados contradictores y opositores de la negociación. 
político la posición de su partido, el Centro Democrático, respecto a rechazar lo que en ese momento se discutía y se acordaba en la mesa de negociación de La Habana, planteando, como mecanismo, hacer oposición al proceso de negociación a través de una "resistencia civil". La entrevista insistió y buscó que el expresidente explicara con claridad a qué se refería cuando invocaba la "resistencia civil" como ejercicio de rechazo y oposición al proceso de La Habana. Aunque la mayoría de las respuestas dadas por Uribe Vélez fueron vagas e imprecisas, eludiendo ofrecer una explicación diáfana respecto a qué entendía por "resistencia civil", las incisivas preguntas de los periodistas permitieron colegir dos aspectos sustanciales, por una parte, frente a la pregunta de si él asumiría alguna responsabilidad en caso de que el llamado a la "resistencia civil" derivara en expresiones o manifestaciones de violencia, sostuvo:

... la verdad es que la pregunta no tiene razón de ser... usted no tiene de qué preocuparse por ese tema, porque lo nuestro no se ha salido de los cauces de la Constitución... yo lo que no quisiera es ser responsable de la entrega del país a las Farc...

Por otra, indicó las fuentes que inspiraban su propuesta: santo Tomás y Laureano Gómez Castro:

... desde hace varios siglos, santo Tomás propuso la resistencia civil. En Colombia, hay unos escritos bien importantes de Laureano Gómez sobre la resistencia civil pacífica. El liberalismo la propuso para no participar en las elecciones de $1950 \ldots$

Como lo sugiere el escritor y periodista Antonio Caballero en sus columnas dominicales publicadas por la revista $S e m a n a^{3}$, las posturas de Álvaro Uribe Vélez parecieran replicar las asumidas sesenta años atrás por Laureano Gómez, tanto en lo que atañe a la "resistencia

3 Se destacan "El fantasma del comunismo", publicada en la edición del 12 de marzo de 2016 y "Hacer invivible la república", publicada en la edición del 14 de mayo de 2016. 
civil" para oponerse a lo acordado en La Habana, como a la propuesta de hacer un gran "pacto nacional" que posibilite salvar los acuerdos con el grupo insurgente tras los resultados del plebiscito del 2 de octubre de 2016. Señala Caballero (2016):

El expresidente Uribe lo resume: que si se hace un "pacto nacional por la paz" entonces él "se compromete a ayudar en la implementación en el Congreso". Qué generoso: ofrece no oponerse a la implementación de lo que él mismo anuncia que va a firmar, insinuando que si quisiera podría oponerse para lograr más gabelas. (Lo mismo hacía hace 60 años el entonces expresidente Laureano Gómez cuando firmó los acuerdos de paridad conservadora-liberal del Frente Nacional para después oponerse a ellos, como chantaje que le sirvió para conseguir además la alternación presidencial entre los dos partidos. Primero copió lo de "hacer invivible la república" con su "resistencia civil”; y ahora esto. No hay duda de que Uribe está leyendo una biografía de Laureano. ¿Tal vez la clásica Psicoanálisis de un resentido del profesor Socarrás?). Porque no es un pacto lo que propone, sino una capitulación. Sus propuestas patrióticas —y deliberadamente inaceptables— las cierra con su quejumbroso tono de mártir: "Todos queremos la paz. Lo que nos preocupa es la necesidad de introducir reformas a los textos de La Habana". Unas reformas que impliquen la rendición sin condiciones. No solo de las Farc: que entreguen sus armas y sus dineros y vayan mansamente a la cárcel y renuncien a la vida política. Sino también una rendición del presidente Santos y el abandono de sus políticas de restitución de tierras y de ayuda a las víctimas del despojo paramilitar; y una entrega de los negociadores de La Habana y de los que votamos Sí en el plebiscito por los acuerdos de paz.

Las resonancias, no obstante, van más allá de invocar a la "resistencia civil" como instrumento de oposición frente a los acuerdos de La Habana. Bien sea por convicción o por instrumentalización del discurso, Álvaro Uribe Vélez abreva de la voz y del ideario del emblemático líder conservador para cuestionar/discutir temáticas sensibles que en la segunda década del siglo xxı buscan superar por 
la vía negociada una confrontación política, social y armada con los grupos insurgentes, entendiendo que Uribe Vélez ha negado la existencia de la guerra, reduciendo a los alzados en armas a simples narcoterroristas. De igual modo, las posturas del expresidente interpelan temáticas y discusiones sensibles en la Colombia contemporánea, tendentes a reconocer expresiones ciudadanas e identitarias que emergen en contextos políticos y sociales caracterizados por un intenso debate en torno a la alteridad, el multiculturalismo y la interculturalidad. En consecuencia, cabe preguntar: ¿cuáles son las resonancias de las ideas laureanistas que aún resuenan en las posturas políticas del expresidente y senador?

Para comprender esas resonancias y ecos es necesario hacer un ejercicio analítico que posibilite, primero, desentrañar las estrategias discursivas empleadas por dos hombres públicos que, a pesar del distanciamiento temporal, configuran un mismo campo discursivo —enmarcado dentro de lo que se denomina como político-; segundo, identificar en las estrategias discursivas las intertextualidades que, en un plano inevitablemente diacrónico, subyacen a los dos procesos enunciativos; tercero, identificar las modificaciones que en las estrategias discursivas devienen a partir de los soportes significantes.

El análisis tiene como base conceptual y metodológica los desarrollos alcanzados por el semiólogo argentino Eliseo Verón en torno a la enunciación política (1987), quien caracteriza el campo discursivo de lo político como un enfrentamiento entre enunciadores. Para una mayor comprensión del ejercicio, cabe recordar que, en los estudios que atañen al análisis crítico del discurso, hablar de enunciación o enunciador como categorías implica hacer referencia a objetos abstractos cuyos “anclajes" posibilitan que en las operaciones discursivas se construya la referencia o imagen de lo que se habla o de quien se habla (Ducrot, 1984; Kerbrat-Orecchioni, 1986; Maingueneau, 2009). La precisión es pertinente porque, como lo señala Verón, para el caso del campo discursivo político se configura una hipótesis que no tendría aplicación a otro tipo de campos (verbigracia, informativo, publicitario, jurídico, etcétera). Dado que el acto de enunciación política está destinado 
o dirigido a un adversario ${ }^{4}$, toda enunciación envuelve una réplica o anticipa una en relación con un contrincante, real o posible, que es un destinatario positivo, negativo o indeciso. En ese contexto, el acto de enunciación política tendría un primer nivel de análisis, enfocado a quien se dirige (Verón, 1987, p. 17). Con el propósito de ofrecer una mejor ilustración, se presentarán tres esquemas que sintetizan los conceptos y argumentos de Verón sobre el particular:

Figura 1. Enunciación política

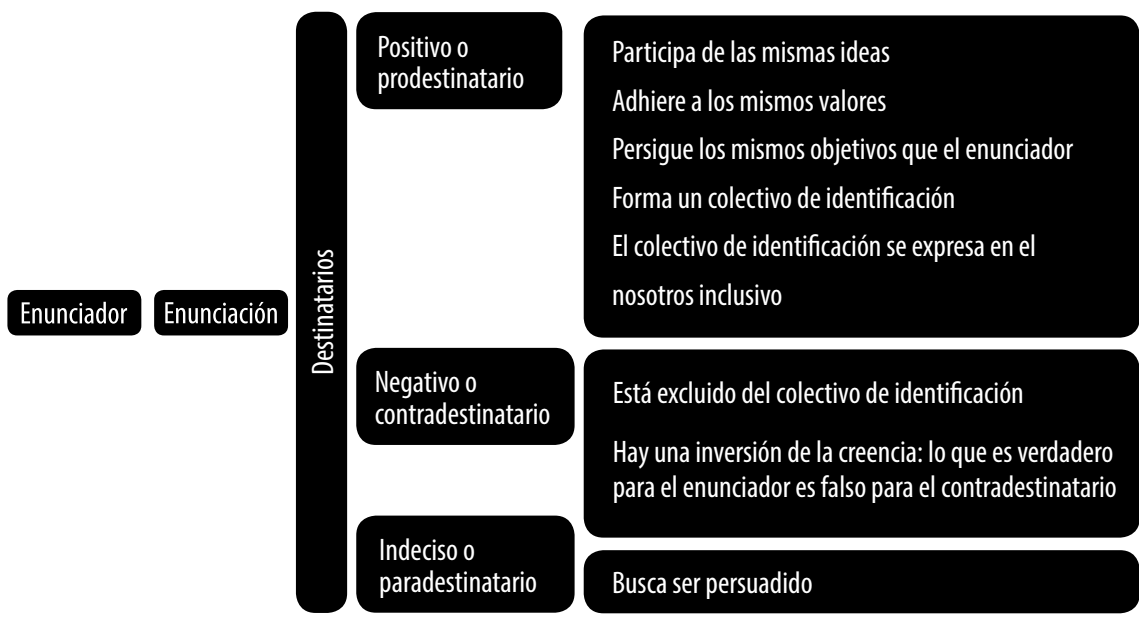

Fuente: Verón, 1987

Un segundo nivel de análisis está en el enunciado, a través de dos tipos de funcionamiento. El primero está en las entidades, las cuales configuran las leyes de composición del enunciado, propiciando juegos discursivos que varían de acuerdo con la construcción del destinatario por parte del enunciador. Nuevamente, los esquemas resultan útiles para ilustrar las categorías analíticas que propone Verón (p. 18).

4 Al respecto, se indica: "Es evidente que el campo discursivo de lo político implica un enfrentamiento, relación con un enemigo, lucha entre enunciadores. Se ha hablado, en este sentido, de la dimensión polémica del discurso político. La enunciación política parece inseparable de la construcción de un adversario" (Verón, 1987, p. 16). 
“Hacer invivible la República”: RefleXiones en torno a la figura de Laureano Gómez Castro

Figura 2. Entidades del enunciador

Colectivo de identificación: También aparece en la enunciación y se lo designa de manera explíita en el discurso a través de la marcación "nosotros". Es enumerable y permite su fragmentación y su cuantificación. Ejemplo:"... nosotros queremos la paz, pero los señores del gobierno y de las Farc piensan que...".

Posición de recepción: Corresponde a entidades más amplias que los colectivos de identificación y que el enunciador político coloca habitualmente en oposición de recepción. También son enumerables:

Ejemplo: colombianos, ciudadanos, compañeros, compatriotas.

Metacolectivas singulares: Son más abarcadores que los colectivos propiamente políticos; por lo mismo no son cuantificables ni se fragmentan.

Ejemplo: el país, la patria, el mundo, el pueblo.

Formas nominalizadas: Poseen un valor metafórico o de sustitución respecto del conjunto de la doctrina de un enunciador 0 una posición política, adquiriendo valores positivos o negativos. Son frases que identifican una postura política.

Ejemplo: "No + diálogos con los asesinos", eslogan de la campaña del No en el plebiscito del 2 de octubre.

Formas nominales: A diferencia de la categoría anterior, estas poseen un poder explicativo, son operadores de interpretación.

Ejemplo: la crisis, el terrorismo, los narcoterroristas.

Fuente: Verón, 1987

El segundo nivel está en los componentes, entendido como modalidades que articulan el enunciado con la enunciación. A través de estos el enunciador construye su red de relaciones con las entidades del imaginario, es decir, los distintos tipos de destinatario (Verón, p. 19).

Figura 3. Componentes del enunciador

Componentes del enunciado

Descriptivo: Es aquel en que el enunciador político ejercita la constatación (balance de una situación). Predominan los verbos en presente del indicativo. Comporta a la vez una lectura del pasado y una lectura de la situación actual. Corresponde a la modalidad del saber.

Didáctico: En este componente el enunciador político no evalúa una situación, sino enuncia un principio general, formula una verdad universal. Las marcas de la subjetividad son menos frecuentes. Los principios se enuncian en el plano intemporal de la verdad. Corresponde a la modalidad del saber.

Prescriptivo: Entreteje el orden del deber y el orden de la necesidad deontológica. Dicha necesidad aparece, naturalmente, como de carácter impersonal, como un imperativo universal 0 al menos universalizable.

Programática: Manifiesta el peso de los fantasmas del futuro, es el componente donde el enunciador político promete, anuncia y se compromete. Predominan las formas verbales infinitivos y en tiempo futuro.

Fuente: Verón, 1987 


\section{Ecos y resonancias}

A partir de los tres esquemas que ilustran las categorías propuestas por Eliseo Verón respecto al discurso en el campo político, el objetivo del apartado está en analizar las intertextualidades que, a manera de ecos y resonancias, hay entre las ideas planteadas por Laureano Gómez Castro y Álvaro Uribe Vélez a través de enunciaciones trascendentales en su momento para el país. En lo que atañe a Laureano Gómez, se escogió "El basilisco", discurso pronunciado el 25 de junio de 1949 en la plaza Berrío de Medellín, cuando retornó de su exilio en España tras los acontecimientos del 9 de abril de 1948. Respecto a Álvaro Uribe Vélez, se escogió la entrevista concedida al periódico $E l$ Mundo de Medellín el 6 de noviembre de 2016, después del plebiscito que convocó a los colombianos para ratificar o rechazar lo acordado en La Habana. Para ilustrar, el ejercicio de contrastación destaca tres resonancias puntuales: 1) la construcción del adversario político, 2) el carácter mesiánico y 3) la resistencia civil.

\section{El retorno del basilisco}

Una primera resonancia está en la construcción del adversario político que los dos estadistas fijan como contradestinatario de la enunciación. Para el caso de Laureano Gómez Castro son varios los discursos - pronunciados entre los años treinta y cuarenta- que dedicó a señalar al Partido Liberal como entidad nominal para explicar su responsabilidad en la crisis social, política y económica que experimentaba el país; crisis que, según Gómez, además de corroer los cimientos morales e institucionales plasmados en el proyecto constitucional de 1886 (2013, p. 178), devenía de las reformas implementadas por los gobiernos de Enrique Olaya Herrera, Alfonso López Pumarejo y Eduardo Santos. Pero es en el discurso "El basilisco" en el que Gómez Castro logra sintetizar, década a década, lo que él consideró fue el ascenso y esplendor que vivió Colombia en el despuntar del siglo xx con la política de la hegemonía conservadora y su posterior debacle con las reformas económicas y sociales promovidas por los mencionados Gobiernos liberales; de igual modo, en "El basilisco" Gómez Castro construye la 
metáfora de la amenaza que, según él, representaban liberales, masones y comunistas (se amplía el abanico de entidades nominales) con la monstruosa figura mitológica, la cual, no se duda desde la enunciación, llevaría al país a un caos mayor.

En la contemplación de panorama político se encuentra el país absolutamente dividido en dos bloques: de un lado se halla el Partido Conservador... El Partido Conservador colombiano tiene un programa y una doctrina. Defiende unos principios a los que considera vinculados al bien común y el bienestar de todos los ciudadanos... Bajo la doctrina conservadora, de una frontera hasta otra, del mar caribe hasta las montañas de los Andes meridionales, todo colombiano sabe por qué es colombiano; profesa idénticas ideas, sirve los mismos principios, tiene iguales anhelos, está consagrado a una altísima labor intachable que cubre todos los aspectos de la vida social... Lo que se denomina Partido Liberal realmente no tiene de liberal sino el nombre que ha caído en desuso sobre el universo de la tierra... el Partido Liberal, que nació en el siglo XviII y llenó el siglo pasado, terminó en el mundo su misión que se apoyaba sobre el emblema de la Revolución francesa... (Gómez, 2013, pp. 312-313).

La figura del basilisco como representación de amenaza y caos para el proyecto nacional, se resemantiza al despuntar del siglo xxi a través de la emergencia de la palabra castrochavismo, como entidad nominal que expresa la amenaza que representan todos aquellos contradictores de las tesis que defiende el expresidente Uribe: desde las Farc-EP y el ELN como grupos insurgentes que buscan a través de la negociación un reinserción a la vida civil; pasando por una serie de organizaciones, comunidades o grupos de carácter civil que con el discurso de los derechos humanos promueven diversas iniciativas reivindicatorias; hasta el propio gobierno de Juan Manuel Santos que, en palabras de Uribe Vélez, somete la democracia en nombre de la paz. El castrochavismo se complementa con otras entidades nominales, siendo las más empleadas por Uribe Vélez la del terrorismo, para referenciar las acciones de 
guerra de las Farc-EP y del ELN, así como la de narcoterrorismo, al catalogar a las Farc-eP como el principal cartel de cocaína del planeta.

Las Farc empezaron como una guerrilla marxista-leninista y han acabado en el narcotráfico. Hoy son el mayor cártel de cocaína del mundo. Fueron protegidas por Chávez en Venezuela. Y ahora, con el acuerdo firmado con el señor Santos, pretenden imponer ese mismo modelo marxista-leninista en Colombia. Es decir, convertir Colombia en una segunda Venezuela... En Europa piensan que Colombia ha pasado de la guerra de Uribe a la paz de Santos. Eso es falso. Durante mi mandato, Colombia ganó inmensamente en seguridad. Si quiere, en paz. No buscamos la aniquilación de los grupos guerrilleros, sino su desarticulación. El acuerdo de Santos con las Farc, en cambio, genera impunidad, fortalece un modelo marxista-leninista y no combate el narcotráfico. Llamaron paz a la democracia sometida (El Mundo, 2016) (Resaltado fuera de texto, distingue las marcas discursivas).

\section{Salvadores del caos político y moral}

Una segunda resonancia está en el carácter mesiánico que ambos personajes construyen en la enunciación, con el fin de justificar sus respectivas intervenciones para enfrentar las amenazas que representan el basilisco y el castrochavismo, respectivamente. La enunciación esgrime los "intachables" valores políticos y morales que caracterizan al hombre conservador, para argumentar que tanto él como el Partido tienen un papel histórico: reconstruir y salvaguardar el proyecto civilizatorio del país. En consecuencia, el discurso, pronunciado en plaza pública, busca explicar los motivos del retorno tras el periodo de exilio en España, estableciendo con claridad un adversario o contradestinatario: el Partido Liberal, los masones y los comunistas, representados como un gran monstruo que, además de constituir una amenaza, es el responsable de la violencia desatada en las zonas rurales. En ese contexto, cabe destacar dos aspectos: 
1. La configuración del contradestinatario está sobre la base de construir un colectivo de identificación integrado por los miembros del Partido Conservador, cuya presencia en la plaza pública también conforma un cuerpo significante que ofrece respaldo al líder; por lo mismo, los asistentes se constituyen en un enunciador colectivo que también asumen la responsabilidad de la enunciación. Dado que el discurso es transcrito y publicado al día siguiente en el editorial del periódico El Siglo, el colectivo de identificación se amplía e incluye a los lectores del diario capitalino. Al respecto, el inicio del discurso resulta muy ilustrativo, además de las marcas discursivas de primera persona del singular (“yo"), que buscan demostrar el compromiso que tiene el enunciador con el Partido, el país y el momento histórico. Asimismo, contiene menciones colectivas con marcas discursivas de primera persona del plural ("nosotros") que apelan a una experiencia de violencia vivida por él y por otros en un pasado reciente que no se debería repetir:

Aquí estoy otra vez en medio de vosotros para responder presente en la realidad de la vida como he estado siempre en la comunión de los espíritus y en el sentimiento... Es tan poderoso el impulso que me atrajo que, al ver realizado mi propósito, me exalto de alegría, porque es un don de la suerte poder iluminar la existencia con la luz que sale de esas pupilas como las vuestras, encendidas por un ideal purísimo y poderse mezclar al ardor y al fuego... Los hombres de mi edad tienen un testimonio valiosísimo que dar a las nuevas generaciones actuales. En la infancia alcanzamos a percibir el odio extremo de la última lucha civil que regó los campos de la república de desolación y muerte... Y ese es el testimonio que tenemos los hombres de mi edad... (Gómez, 2013, pp. 310) (Resaltado fuera de texto, distingue las marcas discursivas).

2. Al definir a los liberales, masones y comunistas como amenaza y responsables de la violencia, el enunciador buscó minimizar la responsabilidad que dirigentes y militantes del Partido Conservador tuvieron en las masacres perpetradas en las zonas 
rurales. Por ello el discurso presenta un componente descriptivo que registra un balance de la transformación que experimenta el país, década a década, en una enunciación que si bien rechaza la violencia como forma de acción política, al mismo tiempo invita a los miembros del Partido a enfrentar a ese basilisco. La invitación trasciende al colectivo de identificación y se dirige a un paradestinatario a quien intenta convencer para que se una a la cruzada contra el monstruo.

Para mí, personalmente, fue un desencanto, fue una desilusión máxima, ver que ese respeto por la vida humana, que en toda $m i$ juventud había visto como esencial para la gloria y para el porvenir y la firmeza de nuestras instituciones, se perdía, se desataba y empezaba lo que tanto hemos lamentado: la matanza como forma de acción política... Ahora bien: para los colombianos todos, pero muy particularmente para los conservadores, la vida sin libertad no vale la pena ser vivida... (Gómez, 2013, pp. 312) (Resaltado fuera de texto, distingue las marcas discursivas).

En lo que atañe a Álvaro Uribe Vélez, es frecuente que sus discursos y pronunciamientos apelen al mesianismo para justificar sus posturas y su presencia en la vida pública, entendiendo que lo usual es que los expresidentes se distancien de los debates políticos tras cumplir su periodo de mandato. No ha ocurrido así con Uribe Vélez, quien interviene, según sus palabras, en "defensa de la democracia colombiana". Los enunciados mesiánicos tienen como base la defensa de la política de seguridad democrática, implementada por el propio Uribe Vélez durante sus dos periodos presidenciales (2002 a 2010). Lo curioso es que la revisión documental permite colegir que la seguridad democrática no tiene un sustento ni conceptual, ni ideológico ni político ${ }^{5}$, aunque Uribe Vélez insista en concebirlo como

5 Además de los documentos gubernamentales, se destaca el libro No hay causa perdida (2010) donde el expresidente registra las justificaciones de sus políticas como mandatario, sustentadas en tres pilares: seguridad democrática, confianza inversionista y cohesión social. 
un "valor democrático" en sí mismo. La seguridad democrática —que se distancia, según el expresidente, de la doctrina de la seguridad nacional en la medida en que es respetuosa de la Constitución, las leyes y los derechos humanos- es el estandarte para contrarrestar a un grupo insurgente calificado como "terrorista", que, además, se convirtió en el "cartel de droga más grande del mundo". Bajo esas entidades nominales (terroristas y narcotraficantes) Uribe Vélez yuxtapone los dos grandes monstruos contemporáneos que las sociedades democráticas temen y combaten en la actualidad.

Teniendo como base la entrevista concedida al periódico El Mundo, revisemos los argumentos del expresidente, los cuales se reiteran en todos sus pronunciamientos públicos e indistintamente del soporte material de la enunciación.

Ya habíamos dicho que las respuestas ofrecidas por Uribe Vélez construyen como contradestinatario al grupo insurgente y al Gobierno de Juan Manuel Santos, pero la enunciación también se dirige a un paradestinatario a quien se intenta convencer de: 1) lo errado que ha sido dialogar con el grupo insurgente; 2 ) dado que hay un acuerdo que pone fin al conflicto, que no fue refrendado a través del plebiscito por un sector de colombianos cuantificable y que integran un colectivo de identificación, este tiene que modificarse, y 3) su presencia debe garantizar que el acuerdo de La Habana no somete la democracia colombiana al castrochavismo. Veamos un ejemplo, destacando que nuevamente las marcas de la primera persona, tanto del singular como del plural, resultan relevantes para determinar la construcción del destinatario:

En mi etapa como presidente, yo hablé siempre de una política de seguridad con valores democráticos. Me preguntaban: "¿Y la paz?". Y yo decía: "La seguridad es el camino a la paz...". Yo no puedo aceptar que el Gobierno y el cártel de cocaína más grande del mundo reformen juntos la Constitución colombiana. En muchos apartados, incluso la sustituyen... Asumamos que las Farc abandonan incluso el narcotráfico. Concedamos el beneficio de la duda a sus 5650 guerrilleros y a los demás grupos criminales. Imaginemos, ahora, que estas Farc post-terroristas entran en política. Los colombianos tendríamos un grave reto por delante: 
combatir el modelo marxista-leninista que los textos de La Habana prescriben para Colombia bajo el insólito amparo de un Gobierno democrático. (El Mundo, 2016) (Resaltado fuera de texto, distingue las marcas discursivas).

\section{Resistir para...}

Construido el contradestinatario y justificada la acción política de intervención para salvaguardar la civilización (Gómez Castro) y la democracia (Uribe Vélez), una tercera resonancia está en esa resistencia civil como instrumento para defender los ingentes valores civilizatorios y democráticos, respectivamente. Imbricadas con las posturas mesiánicas, las enunciaciones en ambos casos van revestidas de una "verdad incuestionable" que adquieren valor por sí mismas. En el caso de Gómez Castro esa "verdad" lleva a una exaltación que invita a los integrantes del Partido Conservador a combatir ese basilisco, esgrimiendo los valores de la justicia, la libertad y la moralidad, con la consecuencia de una "guerra no declarada" que trascendió en los estudios históricos como la Violencia:

Cuando llega uno a estar impregnado de la razón y la justicia de su causa, cuando no tiene un minuto de vacilación porque la verdad lo acompaña, cuando lleva una bandera impoluta entre las manos, entonces, cuanto más fácil sea la lucha, con más alegría debe ser acometida, con más fervor, con mayor ánimo, porque ninguna cosa de valimiento, ninguna cosa grande y trascendental se hizo sin vencer primero arduos obstáculos. Si tenemos grandes dificultades eso nos está indicando que tenemos una gloriosa tarea por delante. La consigna, pues, es de firmeza implacable, firmeza por la justicia, firmeza por la moralidad, firmeza por la libertad. Donde estamos nos quedaremos y hemos de avanzar. Nadie cuente con que retrocederemos bajo ninguna circunstancia (Henderson, 1984, p. 25).

En el caso de Álvaro Uribe Vélez, las enunciaciones son más ambiguas por las estratégicas mutaciones que los discursos van teniendo de acuerdo con las discusiones/decisiones de coyuntura. Como se sostuvo al 
comienzo del capítulo, antes del plebiscito el llamado se concentró en una resistencia civil como mecanismo de rechazo a los acuerdos iniciales concertados entre el Gobierno y el grupo insurgente; con el triunfo del "No" en el plebiscito, la enunciación cambia en la medida en que ya no pone el acento en la resistencia civil —el pueblo ya se pronunció en las urnas-, pero enfatiza, por un lado, en exigir la construcción de un nuevo acuerdo que contenga las peticiones formuladas por los grupos que lideraron la campaña del "No", y por otro, mantener una actitud vigilante para que el nuevo acuerdo garantice que "la democracia no sea sometida”. Esa invitación a una vigilancia permanente incluye estar alerta a la resistencia en caso de que el Gobierno no acoja las recomendaciones de los líderes de la campaña del "No":

El "No" fue un voto en defensa de la democracia. El "Sí" recogía un sentimiento de ilusión por la paz. Al final, influyó más la pedagogía de las razones del "No" que la campaña de sentimientos del "Sí". En estos tiempos, la razón no suele triunfar sobre los sentimientos... Lo que hicimos fue explicar y desarrollar nuestros argumentos. Nuestras razones. Nuestras objeciones. Cuando empecé la campaña por el "No", mucha gente me advertía: "Uribe, van a acabar definitivamente contigo; si gana el 'Sí', es el final de tu carrera política”. Y yo les decía: "Tengo 64 años, he vivido 128. He sobrevivido a 18 atentados. Tengo este pelo irreversiblemente blanco. Como dicen aquí, 'en esta América tropical: plátano maduro no vuelve a verde'. No se preocupen por mí”. Si hubiéramos actuado por cálculo, no habríamos emprendido esta campaña (El Mundo, 2016).

\section{Ratificaciones, contradicciones y confusiones}

El ejercicio de contrastación entre dos discursos para evidenciar algunas de las intertextualidades permite, grosso modo, colegir dos aspectos relevantes: 
1. En su estudio sobre el origen y difusión del nacionalismo, B. Anderson dedica un capítulo a analizar la formación de los Estados nacionales americanos durante finales del siglo XVIII y comienzos del xix, al considerar que representan un asunto inusual respecto a los factores que posibilitaron los nacionalismos de los estados europeos. Por una parte, señala Anderson, la lengua no fue un elemento diferencial en relación con las metrópolis imperiales ni para el caso de Brasil, Estados Unidos o el resto de naciones que se emancipan de la Corona española. Por otra, para el caso de Centroamérica y Suramérica, los movimientos independentistas fueron liderados por una emergente "clase media" que no buscó llevar las "clases bajas" a la vida política y, por el contrario, siempre temió un levantamiento de las poblaciones indígenas y negras (2011, pp. 77-78). En otras palabras, esas emergentes "clases medias" como euroamericanos o criollos que fueron cimentando una conciencia política como grupo social, buscaron reivindicar a través de las movilizaciones su condición de igualdad frente al trato de una política imperial que siempre los redujo a españoles no peninsulares, legitimando su condición de inferioridad al nacer en un hemisferio salvaje, así como su incapacidad para asumir responsabilidades político-administrativas (p. 95). En los movimientos de insurrección, que derivaron en procesos de independencia, las "clases bajas" no estaban representadas. Por el contrario, como lo señala el propio Anderson, recordando las palabras de Pedro Fermín Vargas - liberal colombiano de principios del siglo xix que participó activamente en el proceso expedicionario liderado por José Celestino Mutis-, la valoración frente a los indígenas siempre fue de "hispanizarlos" por considerarlos como parte de una raza degenerada, además de ociosos y estúpidos frente a los esfuerzos "humanos normales" (p. 32). La evidencia histórica también demuestra que, alcanzada la independencia de la Corona española, amplios sectores de las nacientes repúblicas se opusieron siquiera a discutir la abolición de la esclavitud y mucho menos a concebir al negro 
como un sujeto de derecho que pudiera ejercer su condición de ciudadanía.

En consecuencia y aterrizando en el caso colombiano, no resulta arriesgado sostener que en la construcción del proyecto nacional la discriminación, la exclusión y la segregación a la diferencia -étnica, religiosa, política o sexual- sea una constante en el discurso y en la actuación de la dirigencia política. A pesar de las distancias temporales que separan a dos personalidades como Laureano Gómez Castro y Álvaro Uribe Vélez, las resonancias se suscitan como resultado de defender una serie de intereses imbricados con realidades estructurales e históricas que revelan datos como:

- De acuerdo con el coeficiente de Gini (donde 0 es total igualdad y 1 total desigualdad) Colombia registra 0.52 (Dane). El estudio de la Cepal para 2015, no obstante, señala que la cifra en realidad es de 0.55 .

- El 1\% más rico de la población colombiana controla el 20.5\% de los ingresos que tiene el país.

- El $77 \%$ de la tierra está en manos de $13 \%$ de propietarios, pero el 3,6\% de estos tiene el $30 \%$ del total de la tierra.

- El $18 \%$ de los propietarios de tierra no tiene formalizados sus títulos. Además, la informalidad entre los pequeños productores supera el $40 \%$.

- El $80 \%$ de los pequeños campesinos tiene menos de una unidad agrícola familiar (UAF), es decir, son microfundistas.

- El $68 \%$ de los predios registrados en Catastro se clasifican en pequeña propiedad, pero esta solo cubre el 3,6\% de la superficie productiva.

- $\quad$ El $70 \%$ de los alimentos que se producen en el país viene de pequeños campesinos. 
2. Entendiendo que las resonancias y ecos se registran indistintamente de las distancias temporales, a lo que se suma el reconocimiento público por parte de Uribe Vélez respecto a indicar que Gómez Castro es una de sus fuentes de inspiración, las enunciaciones evidencian una marcada diferencia entre los dos personajes: Laureano Gómez Castro, adalid del Partido Conservador en un momento histórico en que las diferencias respecto al Partido Liberal eran marcadas, fue una especie de cruzado que lideró la defensa de aquellos valores políticos y sociales que consideró inamovibles para el sostenimiento de la civilización colombiana. Por su parte, el oportunismo e instrumentalización de Álvaro Uribe Vélez — cuya militancia se inscribe en un Partido Liberal que no guarda mayores diferencias respecto al Partido Conservador u otros movimientos emergidos en los últimos años en Colombia-, lo lleva a acoger los argumentos laureanistas en virtud de los beneficios momentáneos que pueda obtener en el cálculo político que subyace a sus enunciaciones/actuaciones. 
